\title{
Measuring the Effectiveness of State Control on the Maritime Transport Sector in Sudan (1990-2018)
}

\author{
Nadah Gilani' ${ }^{1}$, Sayed Ahmad Abdul Ghani Al Ahmadi \\ ${ }^{1}$ Department of Marine Economics, Mohammed Red Sea University, Port Sudan, Sudan \\ ${ }^{2}$ Marine Control, Sudanese Maritime Ports Authority, Port Sudan, Sudan \\ Email: Nadahjelani@gmail.com, Elahmedy201@gmail.com
}

How to cite this paper: Gilani, N., \& Al Ahmadi, S. A. A. G. (2020). Measuring the Effectiveness of State Control on the Maritime Transport Sector in Sudan (1990-2018). Modern Economy, 11, 1771-1790. https://doi.org/10.4236/me.2020.1111121

Received: July 9, 2020

Accepted: November 16, 2020

Published: November 19, 2020

Copyright $\odot 2020$ by author(s) and Scientific Research Publishing Inc. This work is licensed under the Creative Commons Attribution International License (CC BY 4.0).

http://creativecommons.org/licenses/by/4.0/

(c) (i) Open Access

\begin{abstract}
The aim of this paper is to measure the effectiveness of the governmental control of the maritime transport sector during the period 1990-2018. It attempts to answer the questions that arose during the review of the problem and analyzes the available data to extrapolate the state control of the sector. The study also used the percentages as one of the tools of statistical descriptive analysis as well as extrapolation tools, and reasoning to discuss the hypotheses and draw conclusions. The main findings of the paper were: The State shall control the maritime transport sector, but in a manner that is not efficient and effective for the following reasons: 1) The status of the maritime transport sector in the structure of the State differs from that of the sector in the comparative countries. 2) Incomplete legislative system governing the maritime transport sector in Sudan (conventions-laws-regulations-administrative bodies). 3) Overlap of tasks and terms of reference between the maritime administration and the parties operating in the maritime transport sector in the operational and legislative aspects. 4) Lack of academic and research institutions in the field of maritime transport, where there is only the Department of Maritime Transport Economics at Red Sea University.
\end{abstract}

\section{Keywords}

Transport Economics

\section{Introduction}

The State uses a range of methods, tools, procedures and measures in the field of international trade to achieve a range of benefits from international transactions within the system of achieving the macroeconomic objectives of maximizing the 
return of international business transactions, achieving external balance, seriously adapting to changes in the international trading environment. Therefore, the countries of the world pay particular attention to the maritime transport sector because about $90 \%$ of the foreign trade of the countries including Sudan is transported by sea. Therefore, it is important to know the effectiveness of the state control of the maritime transport sector in Sudan Objectives.

\subsection{The Statement of the Problem}

The Maritime Transport Sector finds that the components of the Maritime Transport Sector operate according to an individual strategy that lacks a unified, integrated and comprehensive vision for the development and development of the sector in all its components. This situation makes it difficult to identify the overall performance of the sector and then direct it to achieve limited objectives that can be measured within a certain period of time.

\subsection{The Research Questions}

- Is the State to control the maritime transport sector in Sudan with the efficiency and efficiency required?

- What is the status of the maritime transport sector in the organizational structure of the Ministry of Transport compared to the status of the sector at the level of the countries of the world?

- What are the opportunities available to the maritime transport sector in Sudan to develop for the positive contribution in achieving the objectives of the economic program of the state?

\subsection{The Research Hypothesis}

1) Putting the control in the organizational structure in the Ministry of Transport under the management of the Maritime Ports Authority unable it to perform its full tasks.

2) The situation is different from most of the countries of the world, it is an unfamiliar situation.

3) The opportunities available in the maritime transport sector in Sudan are:

a) Take advantage of the amendment of the status of the control department in Sudan to generalize the benefit from it.

b) Attention to national and international maritime legislation.

c) There is an overlap between the oversight functions and the executive tasks of the Maritime Ports Authority because it is assumed that the Ports Authority itself will monitor the effectiveness of the control system, which comes from its administrative, financial and technical exploitation.

\subsection{The Importance of the Paper}

The importance of this paper is shown in practical terms in that it deals with a subject that has an impact on the maritime transport sector in Sudan, especially 
in light of the internal economic transformations and challenges (in the lack of foreign exchange and the tendency to increase it by encouraging production for export) Towards market mechanisms through programs:

- Economic reform and reform of the civil service.

- Privatization and trade liberalization.

- Adopting export-oriented economic strategies for export.

- The transformation of the economies of international participation and foreign direct investment.

All this makes the paper especially important to know the future of this sector in light of the overall policies for the development of the various sectors of the state is also the paper assessment of the control of the maritime transport sector in Sudan.

\subsection{Objectives of the Paper}

This paper attempts to answer the questions that arose during the review of the problem, analyze the data available to extrapolate the state control of the sector and try to propose practical recommendations that are applicable.

\subsection{Methodology of the Study}

The study also used the percentages as one of the tools of statistical descriptive analysis as well as extrapolation tools, reasoning and reasoning to discuss the hypotheses and draw conclusions.

\section{Literature Review}

\subsection{Sudanese Maritime Law of 1961}

Coincided with the opening period of Port Sudan Port; the law omitted the scope of application and the legal aspects of the vessel and marine insurance focused on the registration of ships and the boarding and landing systems of seafarers.

\subsubsection{The Sudanese Maritime Transport Law for the Year 2010}

The Sudanese maritime law of 1961 is considered to be better than the previous laws, but it requires some revisions and regulations to interpret some articles (Sudanese Maritime Interest, 1961, 2010).

\subsubsection{Law and Regulation of the Sudanese Maritime Ports Authority 1973}

Although it is specific to the ports, but there are some materials that regulate the relationship with other parties in a way that needs some reviews (General Regulations of the Sea Ports, 2015).

\subsubsection{Port Authority Law}

The Port Authority Law is a modern law, but there are some reservations that may lead to overlap of functions and competencies in the maritime transport sector. These reservations are as follows: 


\section{(Chapter I)}

1) Article (2.5) Application to ships in the territorial sea, in application, the maritime law must be mentioned in the maritime law of 2010 because it is to resolve the legal authority (definition of maritime port in the law of the Authority) of the Port Authority Law. Marine services needed for navigation.

\subsubsection{The Definition of Seaport Is}

Where the modes of transport meet other modes of transport and provide all necessary services for maritime trade when comparing the two tariffs:

2) The definition of maritime transport in the interpretations of Article 4 paragraph 4 differs from the concept of global maritime transport (maritime transport means the carriage of goods and persons through sea ports across the oceans, seas, streams, ports and sea channels) while maritime transport is the sector that includes all those Provide services for the ship from ports and companies to transport and supply companies etc.) (Huda).

3) Definition of the operator in the interpretation of Article 4 (paragraph 5) Definition of the operator: means any person providing marine services and facilities at the port under a license issued by the Authority (the Sudanese Maritime Ports Authority) This definition comes out many who provide facilities in The port is issued under licenses issued by other sovereign entities (trustees and customs), insurance companies, supervising bodies and supervisors.

\subsubsection{Chapter II}

Article (5/6) a) The purposes of the Authority (the promotion of the maritime ports and maritime transport sector through the organization of its administrative and structural affairs, modernization and promotion of investment therein, supervision and control of the seaports and maritime transport sectors).

The maritime transport sector includes about 51 sub-sectors which can be increased. Ports cannot control and supervise these sectors because of the different functions of the ports from the functions of these sectors because there is no structural or organizational relationship between these sectors administratively and the seaports do not have the administrative and executive right.

\subsubsection{Article 6 b)}

(Development of technical standards, requirements and controls for the security and safety of seaports, dry ports and maritime transport).

The requirements of safety of maritime transport for the ports, for example, the requirements of safety of seafarers and workers on ships There are international conventions and treaties signed by the State and incorporated into the domestic legislation to regulate the relationship between ship-owners and maritime workers All this process to enter the seaports at any stage of the stages against the rest of the elements of the maritime transport sector.

\subsubsection{Article 6 c)}

(Regulation of Maritime Transport and Control of Commercial Vessels), Mari- 
time Transport Movement includes the movement of maritime portals or the maritime trade of Sudan (exported and imported) starting from the starting point to the end point. One of these parties is that it cannot regulate the roles of other parties in the service of maritime trade.

Ports have only control over ships within the port basin. Control of ships, such as the State of Science and the Control of the State of the Coast, is not the responsibility of the Maritime Ports Authority.

\subsubsection{Article 7 a)}

Development of maritime transport policies:

7) b) 1): (regulating the ports and maritime transport sector, supervising and setting the general policies for maritime transport and regulation of the maritime transport sector), but it is noted that the maritime ports do not have the powers or the technical and structural units to carry out this task.

Article 7 c) Second: (Preparation of ports, transport and maritime security systems and monitoring their implementation).

7) d) Third: (Preparation of maritime shipping cartels and identification of marine routes and prohibited areas freely consulted and useful in coordination with the relevant authorities).

(D) Fourth: (Issuing regulations for investment in the field of maritime transport services in coordination with the relevant authorities).

7) e): (Licensing of ports, berths and dry harbors for any person where the public interest is required according to the maps of the destination and license).

7) g) Second: Supervising the protection and safety of the environment against any harmful effects of navigation in accordance with the Environment Law and international treaties and conventions ratified by the Sudan.

I) Representation of the State in the international organizations concerned with maritime affairs and maritime transport, attending its meetings and conferences and following up the implementation of the approved decisions and recommendations after their adoption in accordance with the procedures established in the State.

J) To attract national cadres for the development of port and maritime transport services in accordance with the relevant laws in coordination with the relevant authorities.

7) 1) The adoption of certificates of qualification and the issuance of marine documents and supervision of marine education in coordination with the relevant bodies.

N) Declare the loss of any marine cargo according to the search and rescue areas after the approval of the competent minister (Ministry of Justice, The Official Gazette, 2019).

\subsection{Chapter III: Council}

Article (11): Terms of reference and powers of the Council

Supervising marine extension and shipping services. 
C) Sixth: Organizing technical training for maritime navigation activities and setting the standard level for training through specialized institute.

First: Registration of ships, seafarers, shipping agencies and marine posts.

Third: searching for debris and saving it and disposing of it.

E) To determine the qualifications of the crew of the ship and the marine vessels and to lay the foundations for the modification of the efficiency of any crew member to protect the structure within the territorial sea and the high seas. (Source: Maritime Ports Authority Act, 2019).

5) International conventions, treaties and maritime conventions.

\subsection{Fourth}

The position of the maritime transport sector in Sudan from the international maritime agreements

The International Maritime Organization (IMO) has issued a series of conventions and protocols regulating the maritime transport sector, which deals with marine maritime activity, concerned with marine safety, safety of life and the safety of the natural and commercial environment at sea. Some of these agreements have been incorporated into national legislation to facilitate their applications and maximize their benefits; Of maritime customs governing maritime transactions have not yet been incorporated into national legislation.

\subsection{International Agreements that Must Be Ratified by Sudan through the Maritime Authority}

As of 2016, all member states of the Maritime Organization have been subject to international mandatory auditing to ensure that the State complies with the provisions of international maritime conventions. Based on the results of this audit, the country will be classified as countries with the lowest of these agreements in the white list. As a result, the prices of maritime transactions with these countries will be raised from all parties engaged in maritime trade.

Sudan must sign (22) of the (53) international agreements in a free way so that it can enter the white list and actually Sudan is the site of (11) international conventions.

\subsection{Numbering of Agreements Signed by Sudan}

1) Agreements for the establishment of the Organization, ratified by the Minister of Finance 1974/5/5.

2) Amendment of the Agreement Establishing the Organization, signed in 2003.

3) The Convention on the Prevention of Maritime Collision, 1972, signed in 1999.

4) Agreement of loading lines of ships signed in 1999.

5) The Convention for the Prevention of Marine Pollution from Ships, 19731978 , and its amendments and amendments, signed on 21/4/2015. 
6) Convention on Preparedness and Response, 1990, signed on 21/4/2015.

7) The African Charter of Maritime Transport, 2001.

8) The 1992 Protocol to the Compensation Fund C1991FUND.

9) The 2003 Fund of the Compensation Fund.

10) International Convention on the Intervention of the High Seas (TERVENTION) of 1963 and its Protocols of 1969.

11) Convention on Civil Liability for Marine Pollution from Ship Fuels.

12) International Convention on Wrecks (Antwerp).

\section{Methods}

\subsection{The First Axis: Objectives of State Intervention in the Maritime Transport Sector}

The State shall intervene in order to control and positively influence the factors of the maritime market in order to achieve the following objectives (Figures 1-5):

1) Developing the maritime transport sector to achieve the planned economic benefits and benefits

2) Raising the level of maritime safety and maintaining a safe and clean marine environment (Mahmoud, 2013)

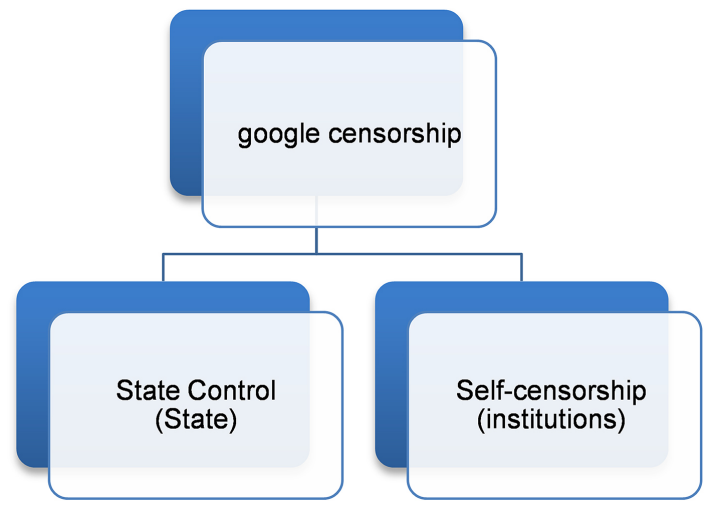

Figure 1. Control of the maritime transport sector. Source: (Prepared by the researchers, 2019). Self-censorship is an internal control exercised by institutions to ensure the integrity of their operations and their conformity with approved plans and programs.

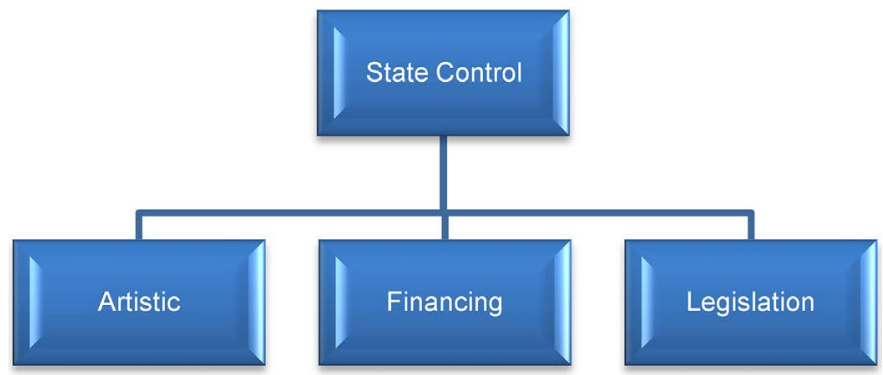

Figure 2. Species state control of the maritime transport sector. Source: (researcher, 2019). State Control: It is the sovereign control exercised by the State on all institutions operating in the maritime transport sector. 


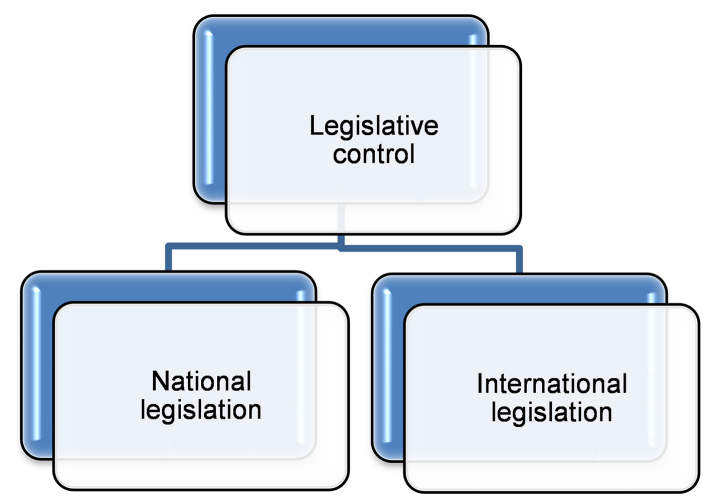

Figure 3. Species of a legislator. Source: (researcher, 2019). State Control: It is the sovereign control exercised by the State on all institutions operating in the maritime transport sector.

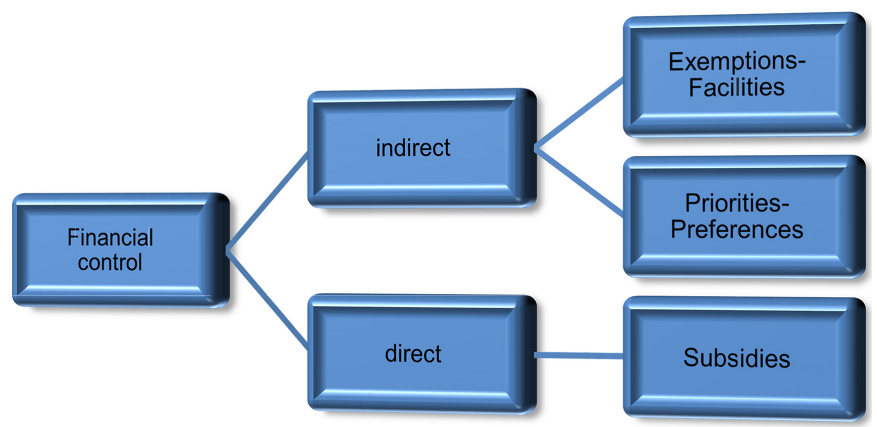

Figure 4. Species of Financial control. Source: (researcher, 2019). State Control: It is the sovereign control exercised by the State on all institutions operating in the maritime transport sector.

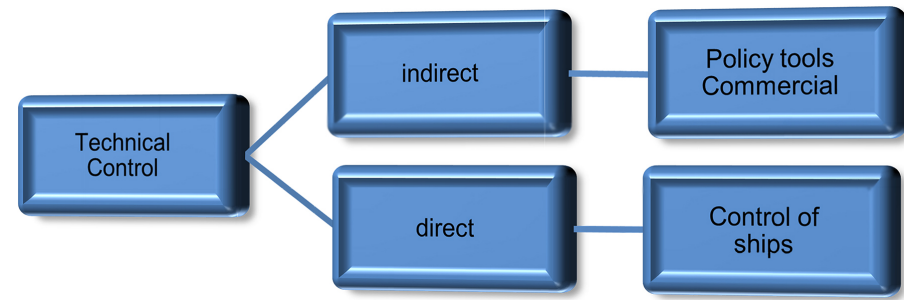

Figure 5. Species of the technical supervisor. Source: (researcher, 2019). State Control: It is the sovereign control exercised by the State on all institutions operating in the maritime transport sector.

Control of international legislation is the control of the state and its follow-up to international and regional maritime legislation, which the state must ratify and sign and then incorporate in the form of binding national legislation.

Financial supervision is to finance the operations of the maritime transport sector to help them produce, provided that they are able to work alone without technical support after an agreed period so that they can compete in the global market.

The objective of technical control is to maintain a certain level of goods and services in the maritime transport market through commercial policies (customs 
duties, import quotas, licenses), as well as maintaining a certain level of ships coming to the port through port state control.

\subsection{The Second Axis}

First: The development of the State control of the maritime transport sector in Sudan:

Article 4 (4) of the Sudanese Maritime Law of 1961 referred to the establishment of a maritime authority for the control and supervision of maritime activity under the supervision of the Ministry of Transport to regulate the commercial maritime affairs in the Sudan. However, a job was established in the Ministry of Transport under the name of the General Registrar of Ships. In the year 1989, the application of Article (4) of the Maritime Law of 1961 to establish the maritime commercial interest (Hassan, 2003) and the development of the status of the regulatory body as follows (Figures 6-16).

In Figure 5, the functions of the Maritime Authority shall be divided between the General Register of Ships Authority, which is directly affiliated to the Ministry of Transport, and the Maritime Ports Authority (especially the maritime inspection functions with a specific financial fee).

Figure 6 combines all the functions of the maritime authority and the registrar of ships and is directly affiliated to the Ministry of Transport. This situation represents a kind of independence and a high degree of sovereignty.

The Maritime Department started to take care of its tasks and arrange them in the form of administrative units to be appointed for performance such as a follow-up office in Khartoum with the addition of administrative and seafarers affairs units.

The number of Sudanese sailors on Sudanese flag vessels and on foreign vessels and their need to issue records and document the seafarers' certificates has been added.

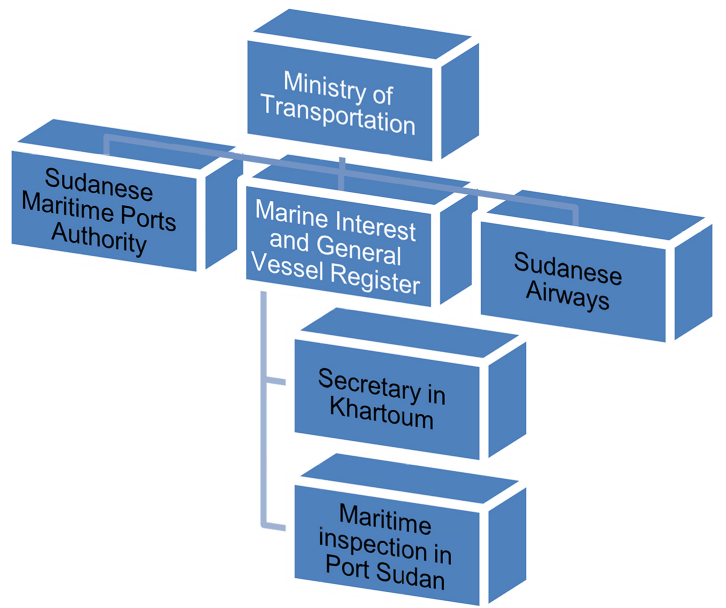

Figure 6. The organizational location of the state control of the maritime transport sector (1989-1996). Source: (researcher, 2019). State Control: It is the sovereign control exercised by the State on all institutions operating in the maritime transport sector. 


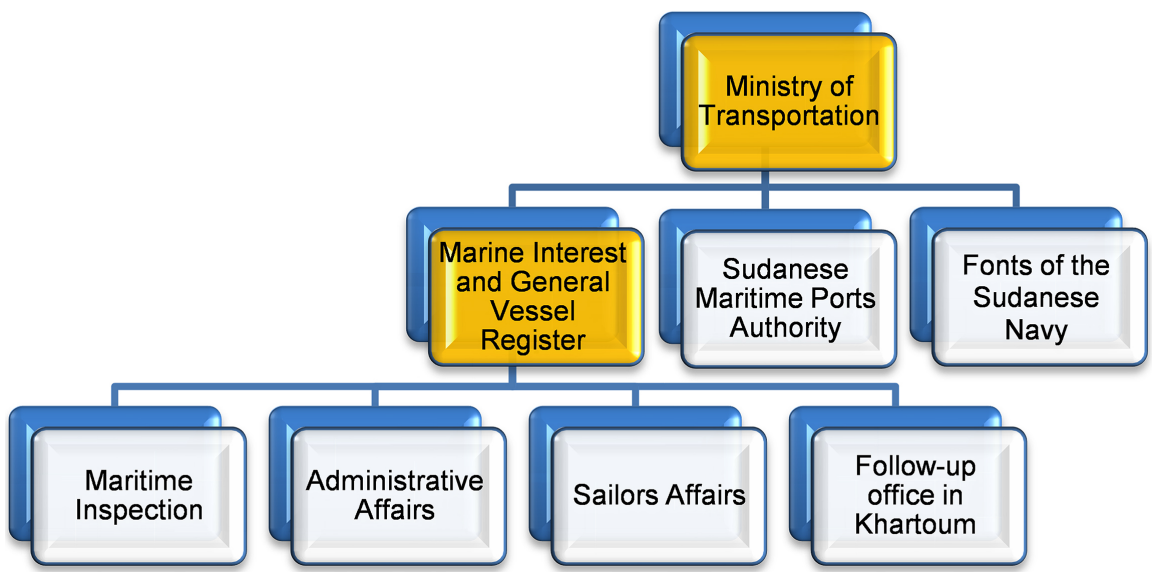

Figure 7. The organizational location of the state control of the maritime transport sector (1996-1999). Source: (researcher, 2019). State Control: It is the sovereign control exercised by the State on all institutions operating in the maritime transport sector.

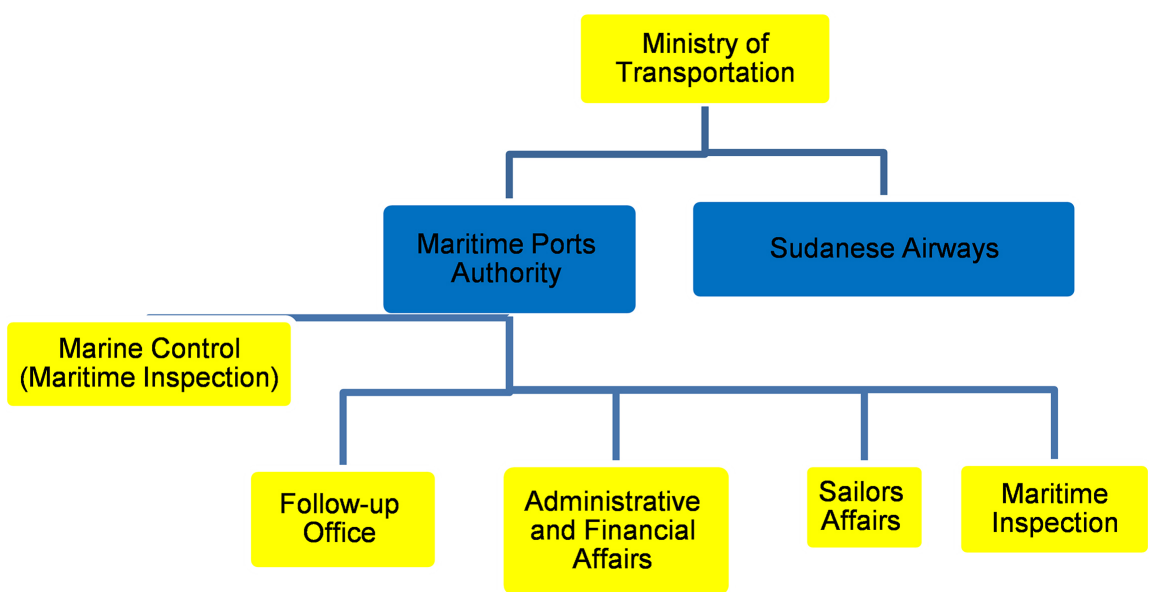

Figure 8. The maritime transport sector (maritime transport section) is directly affiliated to the ministry of transport.

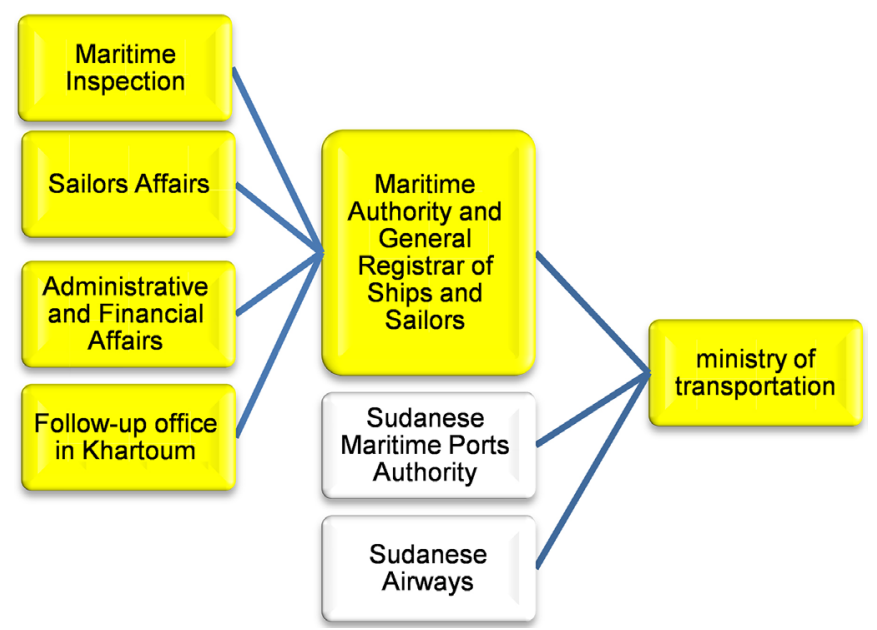

Figure 9. The organizational location of the state control of the maritime transport sector (1999-2011). (Source: The researchers from http://www.smacosd.com/, The Maritime Department). 


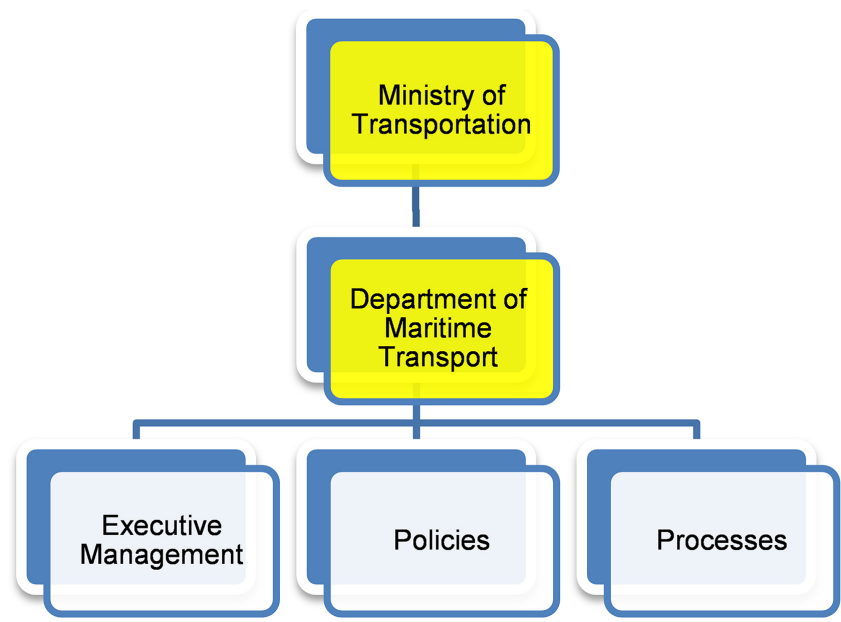

Figure 10. The regulatory position of the control system on the maritime transport sector in France. (Source: The researchers from http://www.mot.gogov.eg).

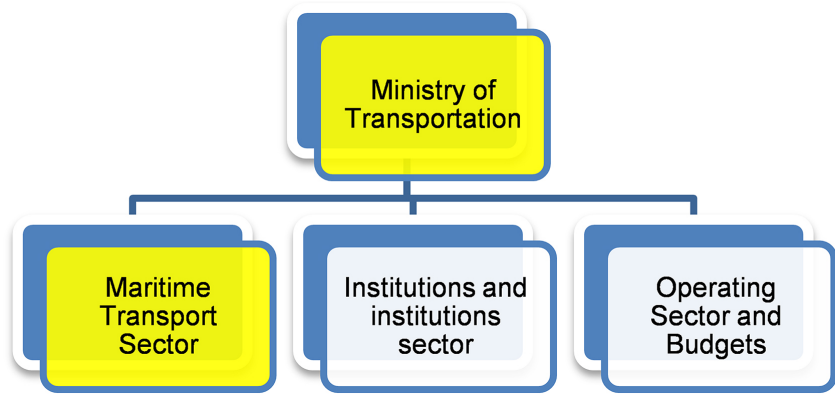

Figure 11. The regulatory position of the control system on the maritime transport sector in Egypt. (Source: The researchers from http://www.mot.gogov.eg).

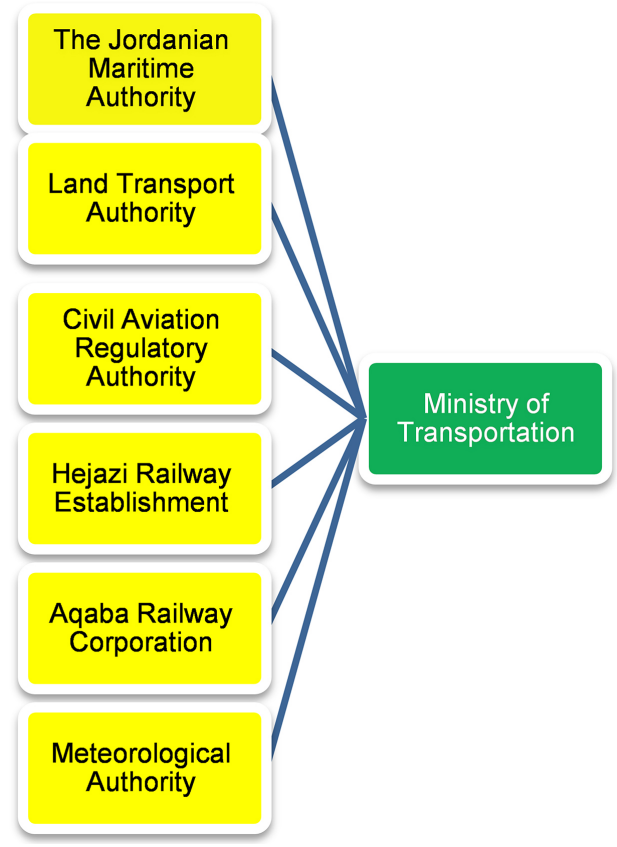

Figure 12. The regulatory position on the control of the maritime transport sector in Jordan. (Source: The researchers from http://www.mot.gov.jo). 


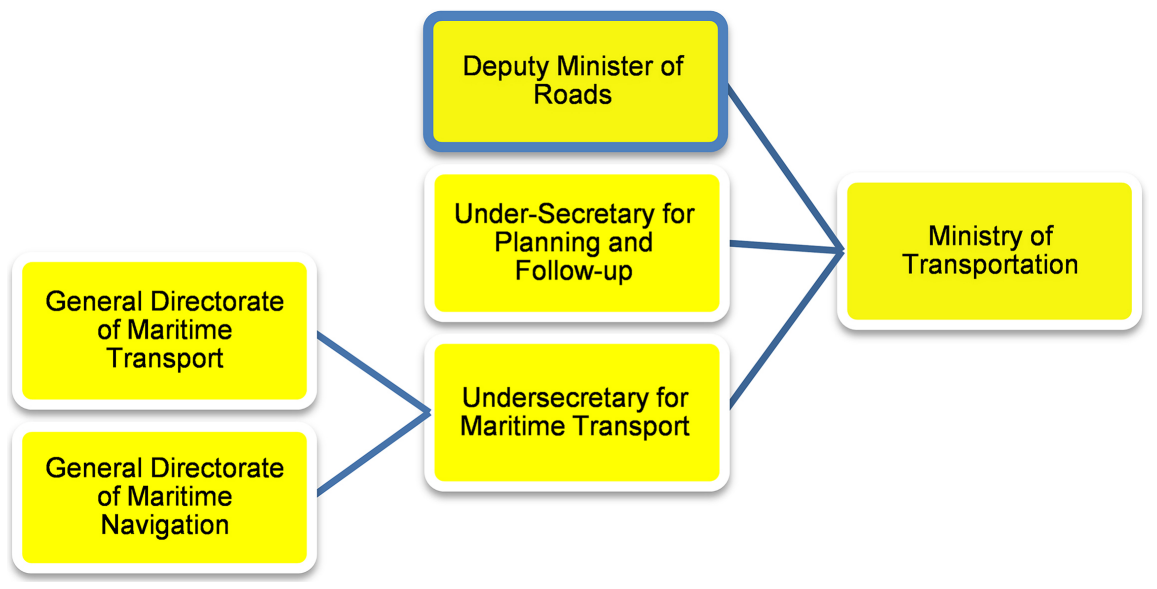

Figure 13. The regulatory position of the control system on the maritime transport sector in Saudi. (Source: The researchers from http://www.mot.gov.jo).

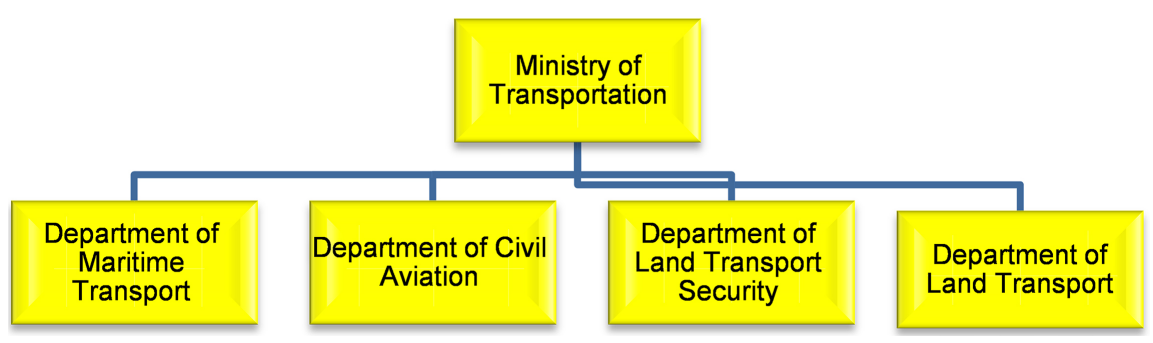

Figure 14. The administrative site of the maritime transport sector in Malaysia. (Source: The researchers from www.mot.gov.jo).

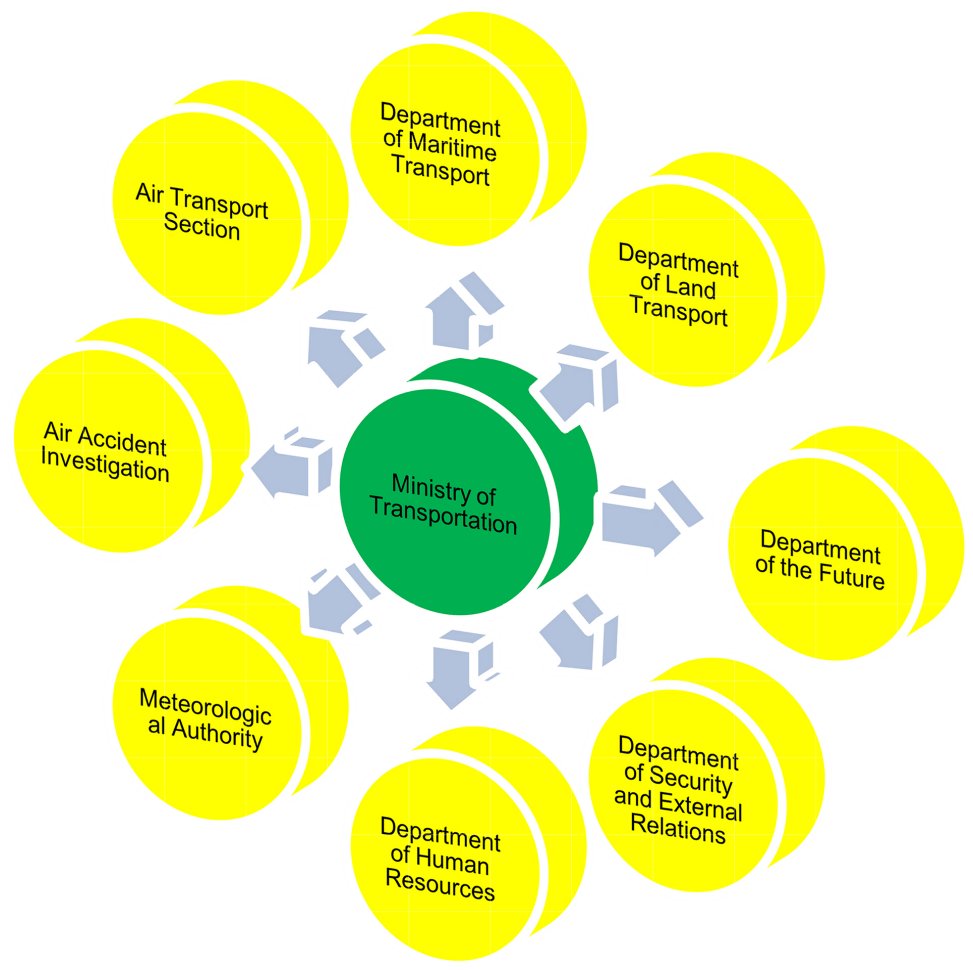

Figure 15. The regulatory location of the control system of the maritime transport sector in Singapore. (Source: The researchers from http://www.mot.gov.jo). 


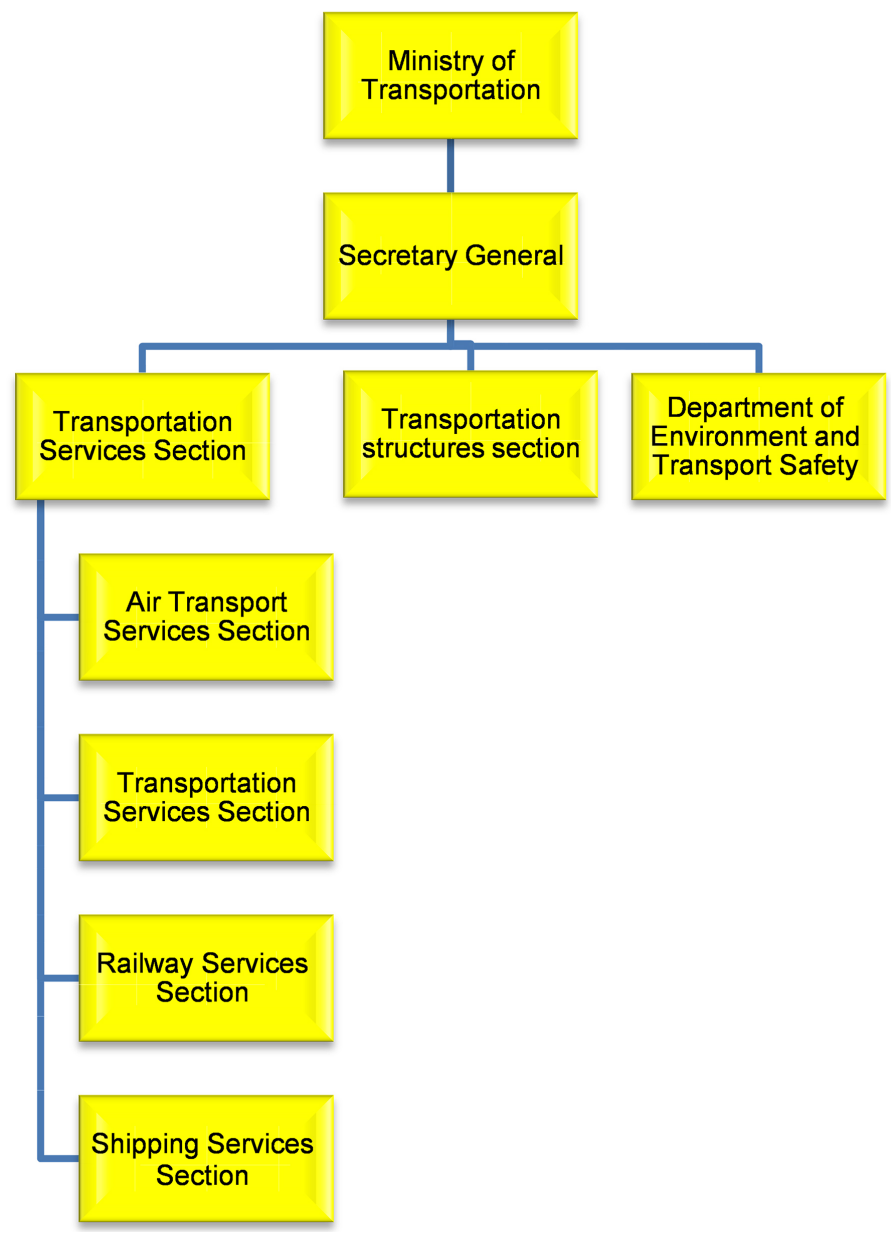

Figure 16. The regulatory site of the maritime transport control system in Tanzania. (Source: The researchers from http://www.mot.gov.jo).

In the year 2012, a presidential decree was issued to abolish governmental bodies and interests. The maritime interest of the Maritime Ports Authority was added and the Maritime Department's functions were carried out by the Maritime Control Department or the Maritime Inspection (as it is sometimes called) Shipping as a whole, including the Maritime Ports Authority.

Second: Examples of the regulatory site of the control body on the maritime transport sector in the world:

It is noted that all the models studied have no exception except that they differ from the model applied in Sudan, where these countries have an independent body in the Ministry of Transport to supervise and control the maritime transport sector with all its components as follows:

The maritime authority of the sovereign control of the maritime transport sector in Egypt is directly related to the Ministry of Transport (Maritime Transport Sector) without an intermediary, which is similar to Figure 9.

The maritime authority in Jordan is called the Jordanian Maritime Authority and this is similar in shape (9).

The Maritime Authority is represented by the Undersecretary of the Ministry 
of Maritime Transport, which is similar to Figure 9.

The Maritime Authority of Malaysia (Maritime Transport Section) is directly affiliated to the Ministry of Transport. This is similar to Figure 9.

Singapore is called the Maritime Authority of the Department of Maritime Transport and the Ministry of Transport and this is similar to Figure 9.

The maritime authority of Tanzania is affiliated with the Maritime Services Section, which has a special section for maritime transport services, which is similar to Figure 9.

We conclude from the comparison between the status of the maritime authority in Sudan compared to the maritime authorities in all countries of the world that this situation cannot (the maritime authority in Sudan) to perform its functions with the efficiency and effectiveness require.

\subsection{Third Axis}

Legislation, laws and regulations governing maritime transport in Sudan.

There is a set of legal systems governing maritime transport that are historically sequenced as follows:

The Law of Transport of Goods by Sea in 1951. The law of the year (1961) (Sudanese Maritime Interest, 1951).

\subsubsection{Agreements with the Council of Ministers}

The Compensation Fund Convention, 1971.

\subsubsection{Agreements with the Ministry of Justice}

1) The International Convention on Civil Liability of 1969 and the 1992 Protocol.

2) The SOLAS 1988 Protocol.

3) Container Safety Convention (1972).

4) NAIROBI Convention on the Removal of Marine Wastes (2007).

5) Rescue Agreement

6) Search and Rescue Convention. SEARCH \& RESCUE 1965

7) Protocol of the Load Lines Convention 1988.

8) Bankers Agreement for the year 2001.

9) Ballast Water Agreement.

10) Memorandum of Understanding Djibouti (2017 AD Jeddah Amendments).

\subsubsection{Agreements Deposited with the Ministry of Transport Until It Is} Ratified by the Ministry of Transport in 2014 (Al Ahmadi, 2003, 2004, 2006)

1) Measuring the effectiveness of control over the maritime transport sector:

The Ministry of Transport is responsible for the supervision of the maritime transport sector under the direct responsibility of the Ministry of Transport. The Ministry's vision is to build an integrated, safe, courteous and efficient transport 
system that responds to the needs of citizens and the national economy.

\section{2) Shipping in the structure of the Ministry of Transport:}

The ministry's new page is a page with the old name of the ministry (the Ministry of Transport, Roads and Bridges). The new name of the ministry (the Ministry of Transport and Infrastructure) does not have an electronic page and there is no such name except in the other news pages.

a) The electronic page of The Ministry of Transport (http://www.motb.gove.sd $(31 / 3 / 2019))$ contains an icon for the organizational structure (student) attached.

b) The logo for the services portal contains the maritime transport services, but only the services provided by the Maritime Ports Authority.

c) page of laws and regulations in the electronic library.

Completely free from any laws and all sectors of transport, including maritime transport with all its components.

d) icon indicators and figures on the page of the ministry has three sub-pages, one of them specific to the indicators of maritime transport, but actually contain performance indicators in the Authority of Ports and Railways for the years (2016-2017).

e) The new port authority law for the year (2019) does not exist in any portal, including the gate of the Ministry of Justice (General Regulations of the Sea Ports, 2015).

3) Measuring the effectiveness of the governmental control over maritime transport in Sudan:

The measure of government control over the maritime transport sector is to rely on the tasks stipulated by the local and international laws as one of the supervisory tasks of the Maritime Authority, which includes about 37 tasks. The percentage will be calculated according to the grades obtained. These tasks are divided as follows:

a) a set of tasks for ships and represented in the number (11) basic task

The evaluation will be awarded with a score of (1) for the tasks being carried out and (5) for the tasks carried out by the Authority in part by the Authority and (zero) for the tasks not performed by the Maritime Authority.

b) A set of tasks for international and domestic legislation and the number (9)

c) Human Task Group (7)

d) Special Tasks Group (4)

e) Environment Task Force (3)

f) Maritime Incident Task Force (3).

Agreements submitted to the Ministry of Justice for the work to be approved by the Council of Ministers and the National Council 2018

1) General ballast water agreement ( ).

2) Container Safety Convention, 1972.

3) Convention on the Determination of Liability for General Ship Owners.

All that is mentioned in the previous axes can be summed up in the form of a table representing (Table 1 ). 
Table 1. Measuring the effectiveness of the governmental control of commercial navigation activity in Sudan (1990-2000) (Mahjoub, 2000).

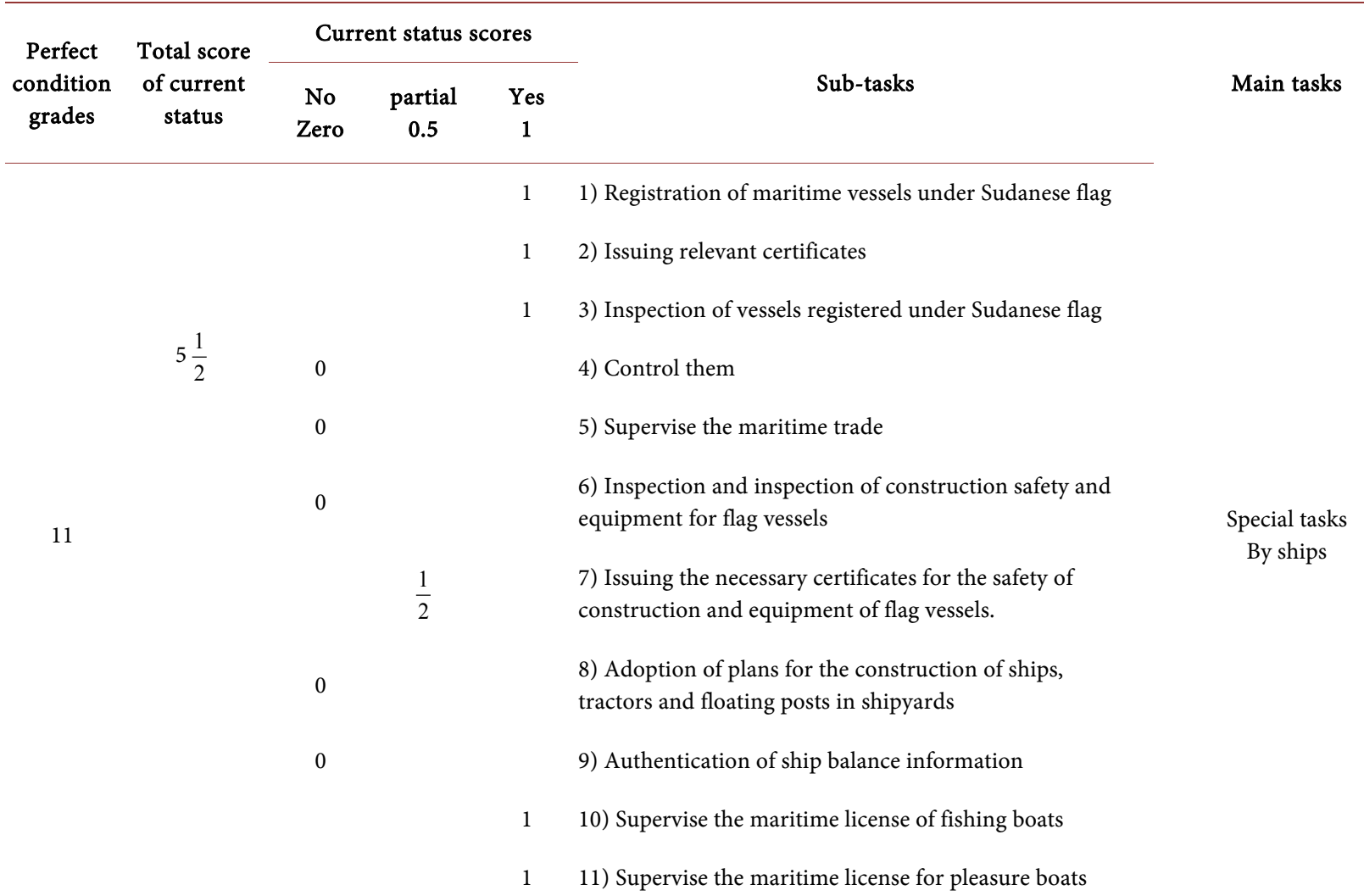

1) The development of new laws and regulations and the observance of international treaties

0

$\frac{1}{2}$
2) Participation in meetings of international organizations

3) Participation in the development of maritime policies according to national plans

4) Application of international treaties signed

5) Follow-up to the decisions of the International Maritime Organization

6) Exchange of information and reports between the States of the Memorandum of Understanding in Port State Control (PSC)

7) Authorization of the international classification agencies to issue some certificates

8) Issue laws and regulations governing fishing vessels

9) Whitelist (list of countries applicable to the Convention on Efficiency, Training and Hafs)
Functions of international and domestic legislation 


\section{Continued}

$$
\frac{1}{2}
$$

7 5 Tasks related to the human element

7) Coordination of maritime training with marine sensors
3) Registration of seafarers

14 ) Issue of offshore books

$1 \quad 5)$ Supervising the rise and fall of seafarers

1) Issuance of certificates of competence and competence for marine officers and engineers

2) Issuing the certificates of the sailors

6) work to solve the problems of seafarers

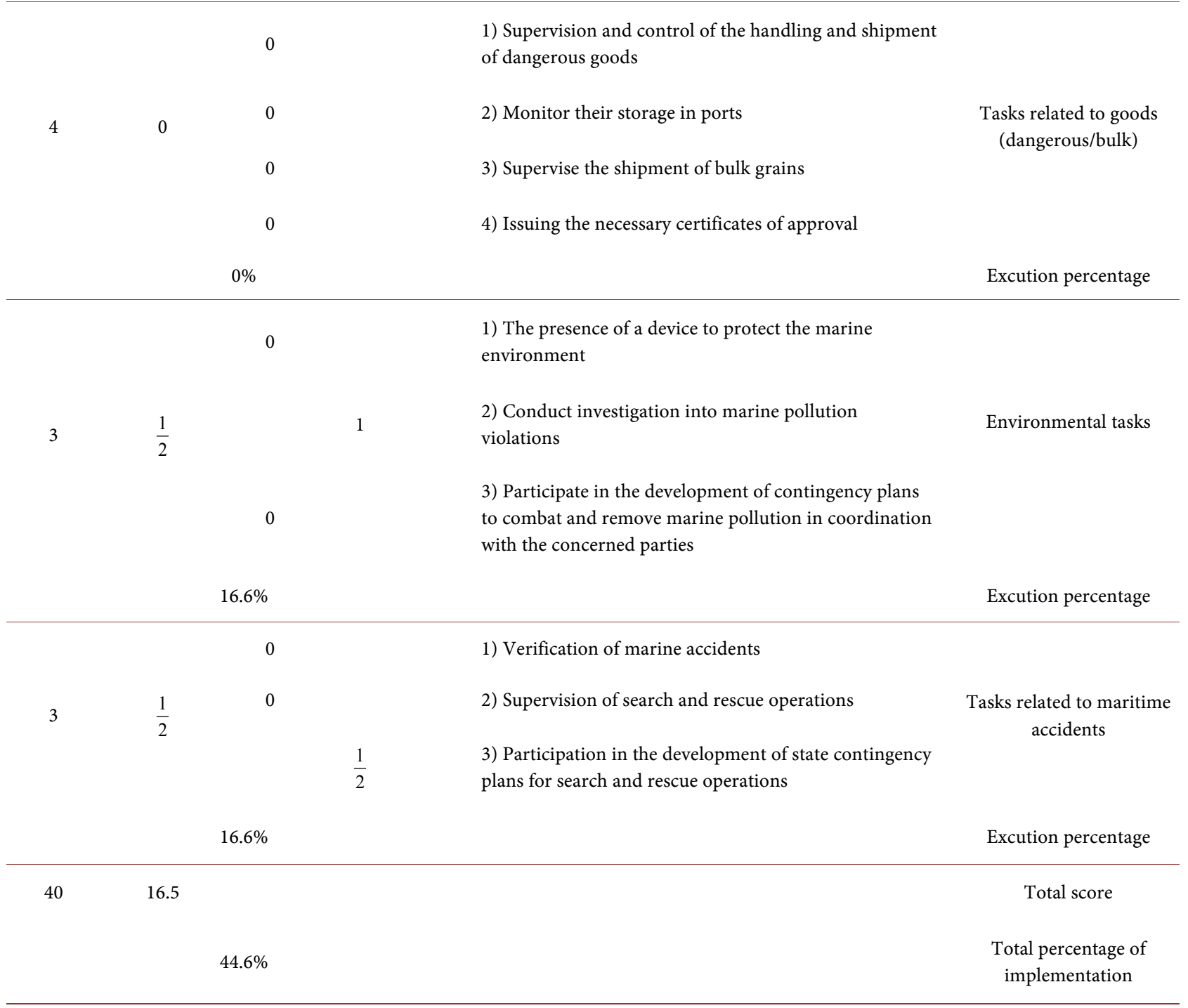

Source: The researchers from http://www.mot.gov.sg. 


\section{Data Analysis}

1) Vessel-related tasks:

The percentage of implementation of tasks related to vessels is $50 \%$ of the optimal ratio of implementation. However, there are some tasks that are not monitored by the regulatory body, in spite of its importance, such as supervising the maritime trade due to lack of specialized human element qualified to carry out these tasks.

2) The tasks related to legislation (international and local) The rate of implementation of these tasks is $55.5 \%$ and often implement a molecule and the reason is due to the current situation of the regulatory body within the departments of seaports in a way that cannot perform these functions as required.

3) The tasks related to the human element (seafarers) were $71.4 \%$, most of them related to the tasks of seafarers' registration, supervision and boarding, and the issuance of offshore books. The tasks related to the other maritime labor (maritime engineers, administrators, law, logistic personnel, maritime agents) It is weak.

The most important tasks related to maritime employment are the issuance of certificates of competence and efficiency for seafarers and marine engineers. These are not carried out by the Maritime Administration because of the current situation of sea control within the structure of the Maritime Ports Authority. It is difficult for them to communicate with IMO to authorize them to grant such certificates. Maritime training with other maritime institutions.

4) The tasks related to the goods (dangerous/bulk).

Maritime surveillance does not undertake any of these tasks because of the lack of material and human resources to perform.

5) Tasks related to the marine environment: The Maritime Control Department cannot carry out these tasks, which are within the port administrations because a large part of these tasks is not suitable for port functions and others need more powers than the current authorities to manage the control and management of the port itself.

6) Tasks related to maritime accidents: The performance of these tasks is very weak due to insufficient physical and human capacity in quantity and quality and the difficulty of coordination with the relevant authorities.

\section{Results}

The State shall control the maritime transport sector, but in a manner that is not efficient and effective for the following reasons:

1) The status of the maritime transport sector in the structure of the State differs from that of the sector in the comparator countries.

2) Incomplete legislative system governing the maritime transport sector in Sudan (conventions-laws-regulations-administrative bodies).

3) Overlap of tasks and terms of reference between the maritime administration and the parties operating in the maritime transport sector in the operational 
and legislative aspects.

Lack of academic and research institutions in the field of maritime transport, where there is only the Department of Transport Economics in the Red Sea University and the Faculty of Maritime Studies, specializing in Military Navy at the University of Kerry.

\section{Recommendations of the Paper}

1) Increasing the level of administrative supervision of the maritime transport sector in the Ministry of Transport.

2) Correcting the status of the maritime administration to become an independent sovereign control body, which is directly related to the Undersecretary of the Ministry of Transport for Maritime Transport Affairs?

3) Clearly define the functions and terms of reference of the maritime regulatory body in line with the requirements of the international community.

4) Reviewing the Sudanese Maritime Law for 2010 and the Port Authority Act of 2019 and completing the deficiencies there in.

5) Utilize the technical support provided by IMO and relevant organizations of maritime States.

6) Incorporate and enforce the conventions and protocols that have been signed by drafting national legislation on their application.

7) Establish educational institutions and research centers for the maritime transport sector to assist in the training, research, development and development of the overall policies of the sector.

8) To benefit from the experiences of the maritime countries that preceded the Sudan in this field.

\section{Conflicts of Interest}

The authors declare no conflicts of interest regarding the publication of this paper.

\section{References}

Al Ahmadi (2004). The Economics of Maritime Transport-Ahmed Abdul Monsef. Alexandria: Al Maarif Foundation.

Al Ahmadi (2006). Transportation Planning and Policies "Events and Merit FactorsSharif Mohamed Maher. Alexandria: University House.

Al Ahmadi, S. A. (2003). The Economics of Maritime Transport- "An Analytical Study on the Relationship between Maritime and Foreign Trade-KarenOlulin (3rd ed.) Translated by Al-Sweify, M., Cairo: The Egyptian Lebanese House.

General Regulations of the Sea Ports 2015-Amendment 2018.

Hassan, N. (2003). State Control of the Flag State and the Limitations of Application in Sudan. Master Thesis of Maritime Academy for Science, Technology and Maritime Transport.

Mahjoub, S. (2000). Maritime Transport Seminar in Sudan. Maritime Management Paper in the Sudan (Past-Present-Future). 
Mahmoud, A. (2013). Maritime Transport Economics and Policies.

Ministry of Justice, Official Gazette, No. 1878, 15/2/2019.

Official Website of the Ministry of Transport, Singapore. http://www.mot.gov.sg Reports of the International Maritime Organization (IMO).

Sudanese Maritime Interest (1951). Sudanese Maritime Law for the Year.

Sudanese Maritime Interest (1961). Sudanese Maritime Law for the Year.

Sudanese Maritime Interest (2010). Sudanese Maritime Law for the Year.

The Maritime Ports Authority Act of 2019.

The Official Website of the Maritime Department-Sudan. http://www.smacosd.com 